\title{
Thermal-Hydraulic Analysis Tasks for ANAV NPPs in Support of Plant Operation and Control
}

\author{
F. Reventós, ${ }^{1,2}$ L. Batet, ${ }^{2}$ C. Llopis, ${ }^{2}$ C. Pretel, ${ }^{1,2}$ and I. Sol ${ }^{3}$ \\ ${ }^{1}$ Institute of Energy Technologies, Technical University of Catalonia (UPC), Avinguda Diagonal 647, 08028 Barcelona, Spain \\ ${ }^{2}$ Department of Physics and Nuclear Engineering, Technical University of Catalonia (UPC), Avinguda Diagonal 647, \\ 08028 Barcelona, Spain \\ ${ }^{3}$ Asociación Nuclear Ascó-Vandellòs (ANAV), Edifici Seu, Apartat Correus 48, L'Hospitalet de l'Infant, 43890 Tarragona, Spain \\ Correspondence should be addressed to F. Reventós, francesc.reventos@upc.edu
}

Received 9 May 2007; Accepted 31 August 2007

Recommended by Alessandro Petruzzi

\begin{abstract}
Thermal-hydraulic analysis tasks aimed at supporting plant operation and control of nuclear power plants are an important issue for the Asociación Nuclear Ascó-Vandellòs (ANAV). ANAV is the consortium that runs the Ascó power plants (2 units) and the Vandellòs-II power plant. The reactors are Westinghouse-design, 3-loop PWRs with an approximate electrical power of $1000 \mathrm{MW.}$ The Technical University of Catalonia (UPC) thermal-hydraulic analysis team has jointly worked together with ANAV engineers at different levels in the analysis and improvement of these reactors. This article is an illustration of the usefulness of computational analysis for operational support. The contents presented were operational between 1985 and 2001 and subsequently changed slightly following various organizational adjustments. The paper has two different parts. In the first part, it describes the specific aspects of thermal-hydraulic analysis tasks related to operation and control and, in the second part, it briefly presents the results of three examples of analyses that were performed. All the presented examples are related to actual situations in which the scenarios were studied by analysts using thermal-hydraulic codes and prepared nodalizations. The paper also includes a qualitative evaluation of the benefits obtained by ANAV through thermal-hydraulic analyses aimed at supporting operation and plant control.
\end{abstract}

Copyright (c) 2008 F. Reventós et al. This is an open access article distributed under the Creative Commons Attribution License, which permits unrestricted use, distribution, and reproduction in any medium, provided the original work is properly cited.

\section{INTRODUCTION}

The main goal of this paper is to illustrate the usefulness of computational analysis aimed at supporting and improving plant operation and control of nuclear power stations. The contents presented below were operational between 1985 and 2001 at the Spanish NPPs run by the Asociación Nuclear Ascó-Vandellòs (ANAV). These power plants are the Ascó reactors (2 units) and the Vandellòs-II power plant. They all are Westinghouse design, 3-loop PWRs with an approximate electrical power of $1000 \mathrm{MW}$. The Technical University of Catalonia (UPC) thermal-hydraulic analysis team worked together with ANAV analysts for an important part of the mentioned period. Although the joint work was fruitful in both innovative engineering and research, the scope of activities currently presented belongs mainly to the former.

The steps that will be followed in presenting the work are

(i) description of specific aspects of thermal-hydraulic analysis tasks related to operation and control, (ii) brief presentation of the results of some of the analyses performed,

(iii) qualitative evaluation of the benefits obtained through such analyses.

The responsibilities of analysts involved in supporting plant operation are somewhat different from those of other analysts that currently produce studies usually found in the technical literature. There could be some coincidences but usually their tasks are quite specific. Support tasks for commercial plants are something alive, and change depending on organizational requirements, status of the plant, and availability of external help. For this reason, there is some subjectivity in what follows below. The almost continuous organizational change of the engineering teams working on operation support corroborates what has been said above. The statement that really defines the function of the operation support analyst is that he/she shares objectives with the engineering team that assists plant operation by means of engineering studies and decision-making. On some occasions, 
TABLE 1: Elements in Ascó and Vandellòs-II models.

\begin{tabular}{lcc}
\hline Elements & Ascó & Vandellòs-II \\
\hline Hydrodynamic volumes & 549 & 613 \\
Control variables & 1454 & 1327 \\
Variable trips & 219 & 234 \\
Logical trips & 431 & 461 \\
Tables & 241 & 227 \\
Interactive variables & 117 & 142 \\
\hline
\end{tabular}

the operation support analyst performs a hundred per cent of the necessary studies. However, quite often, he or she looks through the problem, does a few calculations, draws some preliminary conclusions, and then subcontracts the final analysis to an appropriate engineering company. Subcontracting involves a technical follow-up by the plant analyst, who performs a detailed review that usually includes calculations devoted to check the consistency of subcontractor's results.

In spite of being somewhat subjective, such practises have been operational for quite a long period and have produced interesting results as regards utility engineering and safety issues [1]. Many areas of industry follow this approach. Companies and organizations have certain analytical capabilities and a great knowledge of problems that come up, but they use external help when there are productivity requirements. The examples presented are calculations performed along these lines.

Most of the analyses presented have been performed using integral plant models. These models are best estimate (BE) models and are intended to produce a realistic prediction of the studied scenario. In the case of Ascó and Vandellòs-II NPPs, as in the case of other PWRs, they were prepared long ago [2] using codes such as RELAP5.

Preparing an integral plant model is both a meticulous and laborious task, in which each hydrodynamic system, heat structure, protection and control systems, and the core itself are developed individually, starting from the appropriate design information. Table 1 gives an idea of the degree of detail for each of the models.

Figure 1 shows the main nodalization diagram of the Ascó plant. Both models include another 4 diagrams representing safety injection systems, steam lines, main and auxiliary feed-water (Figure 2), and detailed diagrams of vessel, pressurizer and steam generators (SGs). Figure 8 shows an example of a logic diagram implemented in one of the models. The number of control systems included with a certain degree of complexity, as in the case of Figure 8, is approximately 30 in each model.

The model preparation was made compatible with its use in operation support. Once the models were used, they produced the necessary feedback to improve their performance $[3,4]$. The final result of this development constituted a complete product whose features will be commented below.

The aim of these BE models is to produce a realistic picture of the NPP behavior which will be useful for different kinds of decision-making. The BE models have improved their predictive capacity to a great extent; their results have changed from being a good guidance for general understanding of dynamics to being extremely reliable. If they come together with certain methodology requirements, they might also be valid for licensing and management of margins.

The integral plant models are useful tools for the analysis of dynamic behavior whenever certain requirements are fulfilled. Some of these are related to qualification and documentation [5] of the models and others are linked to case analysis. The most important requirement is the analyst's professional profile [6]. The analyst needs to have the skills to guaranty that

(i) nodalizations have been properly set and adjusted,

(ii) the right options have been activated,

(iii) correct assumptions have been made,

(iv) boundary conditions are those that are needed for the problem.

It is usually said that to produce good results, one needs a qualified user using a qualified nodalization adapted to the problem by means of a qualified code [7]. Analyst training has always been a high-priority issue for ANAV.

\section{ANALYSIS TASKS}

Most of the analysis tasks mentioned in this section are extensively discussed in two different IAEA safety reports $[22,23]$. These documents were developed based on broad international consensus and they describe types and rules for performing computational analyses devoted to both being built and operating plants.

The purpose of this section is not to describe every related task but to add some aspects that are specific of the functions of the analyst working in support of plant operation. Terminology and task descriptions used in this paper are those of the mentioned IAEA reports.

\subsection{Dialogue with regulatory body and fuel designer}

Dialogue backed up by calculation results has been used successfully for many safety issues that have been discussed between the licensee and the regulator or the fuel designer [8]. The BE prediction of a scenario helps communication on any engineering subject related to dynamic behavior. As stated in the introduction, in some cases, the analyst could perform a complete set of calculations aimed at obtaining licensing. He or she could use his or her own nodalization, follow a best estimate plus uncertainty (BEPU) methodology, and come up with results to be directly submitted to the safety authority. In many other cases, results are produced for dialogue $[9,17]$. Sensitivity analysis is the most usual practice of providing support for such communication. It shows clear advantages in relation to engineering judgement based on calculations performed using conservative assumptions.

Going into the technique of sensitivity studies in greater depth, the analyst often ends up sweeping the whole range of a definite parameter and analyzing the impact or the consequences on the final calculation results. In this way, reasonable doubts of real values are clarified. 


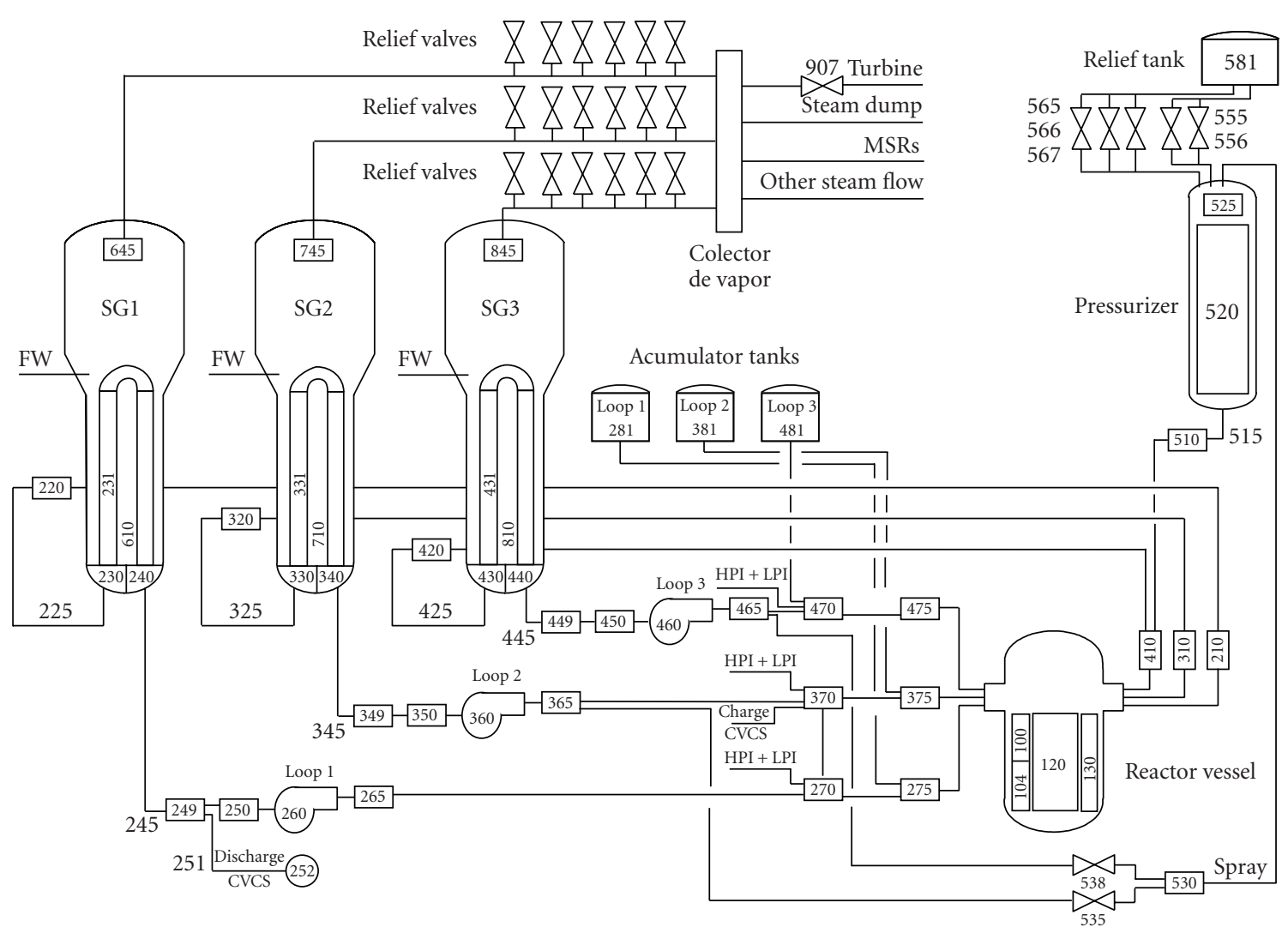

Figure 1: Main nodalization diagram of the Ascó plant.

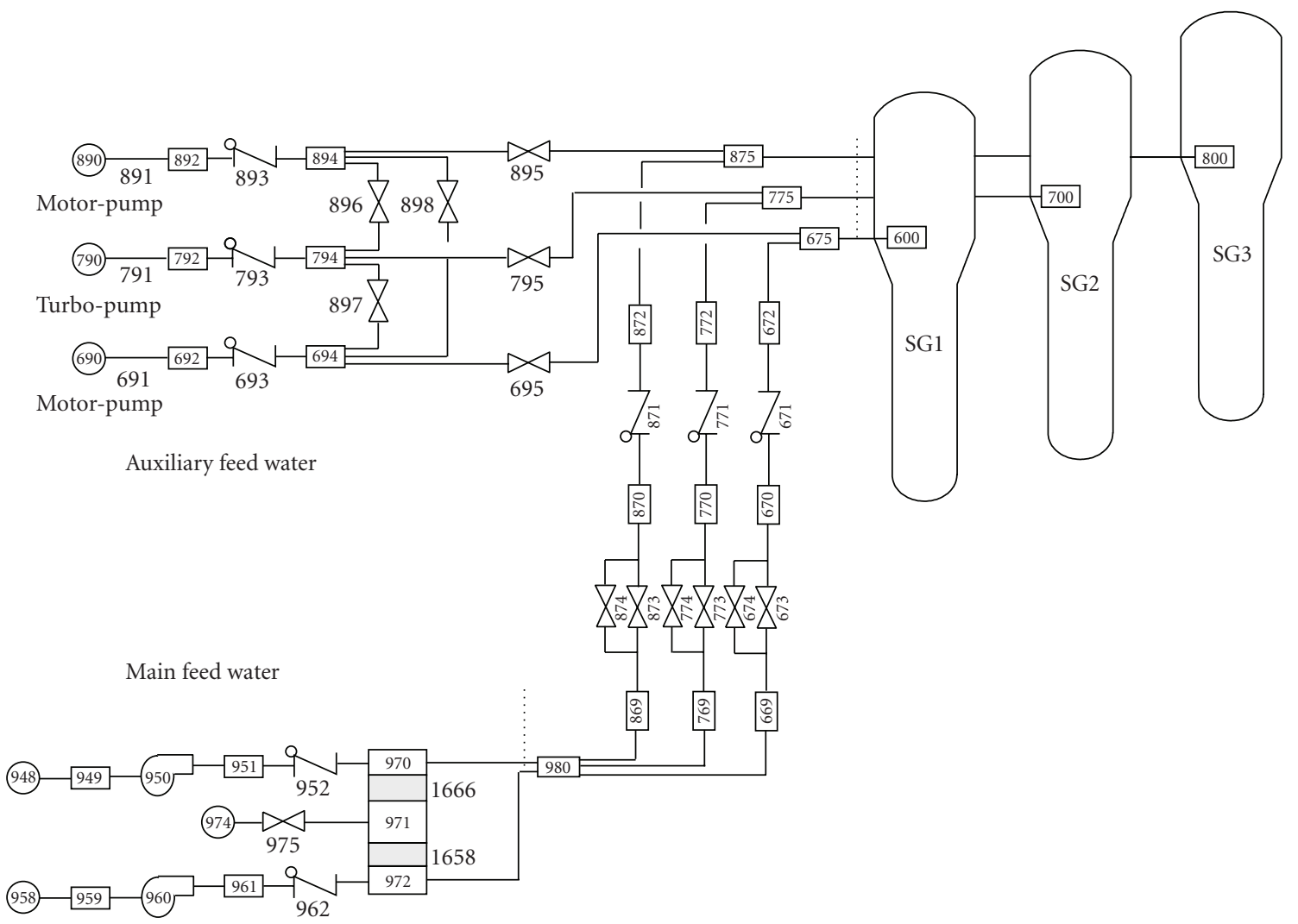

Figure 2: Nodalization diagram of the Ascó FW system. 


\subsection{Thermal-hydraulic analysis of probabilistic safety assessment (PSA) sequences}

The thermal-hydraulic analysis of PSA sequences, mainly those of level 1 , is normally performed using integral BE plant models $[10,11]$. These are a kind of studies in which the IAEA rules given in [22] are normally followed and no additional comments are needed.

\subsection{Analysis of actual transients}

The simulation of actual transients usually produces indepth knowledge of their dynamic behavior. It is also helpful to investigate and to determine the cause-effect relationships of the occurred transient [12-14]. This type of analyses must be performed with high relevance transients or following the request of engineering groups interested in the behavior of the systems involved.

One of the most powerful arguments in favor of these kinds of analysis is that they provide the possibility of generating time trends of functions and magnitudes that are not collected by plant instrumentation. Among these variables are mass flow at any junction (irrespective of whether there is an implemented instrument or not), magnitudes having values outside the instrument range, or other functions such as volumetric fractions of steam in two-phase mixtures.

The most usual objective of this type of analysis is to guarantee that design limits have been kept during the transient. Other objectives are

(i) to eventually clarify the abnormal behavior,

(ii) to answer technical questions,

(iii) to collaborate in follow-up actions (engineering, training, operation, and safety).

\subsection{NPP start-up tests analysis}

The predictive study of NPP start-up tests is extremely helpful for the test coordinator in order to avoid, as far as possible, mishaps, unexpected interactions, and delays that could give rise to economic losses [15]. Competitiveness goals of the electricity business have led the company running the plant to minimize the number of start-up tests to be performed. This kind of analysis helps to reduce the number of tests to only those that have proven benefits for both operation and safety. The expected benefit is usually either better knowledge of dynamic behavior or the correct performance of a system or instrument. This benefit could sometimes be proved by means of a calculation. It is clear that after the implementation of some important modifications to the plant, an extensive set of tests have to be carried out. However, on many other occasions some calculations properly performed could produce the necessary information.

Apart from these important activities related to start-up tests, standard post-test analyses could also become very significant. Important adjustments of the plant model arise very often from the studies carried out as post-test analyses.

\subsection{Analysis of hypothetical transients for operation support}

Emergency operating procedures (EOPs) validation analyses are the most important studies performed that belong to this group. In this case again, no additional remarks are needed as all definitions given in [23] are shared by ANAV-UPC team.

There is also another kind of studies related to operational procedures. They are usually performed at the request of the operation team and are aimed at clarifying any circumstances related to the involved scenario [16]. On many occasions, these studies are aimed at investigating NPP response to boundary conditions that have already actually occurred at another power station.

\subsection{Transient analysis for training support}

There are two different groups of studies in this field analyses for validation of plant training simulators and analyses devoted to direct training actions.

The former is defined in IAEA report [22] and is not needed of any clarification.

The latter is another type of training task that directly uses the results of thermal-hydraulic analyses. At some power stations, dissemination of results from dynamic calculations is organized with the aim of improving the general knowledge of engineers and members of the technical staff. These training tasks are usually assisted by tools that visualize the results of integral plant models. The produced images and animations enable an appealing dissemination of contents which, communicated otherwise, would not be quite so attractive [18]. Therefore, the combined tool (plant model plus visualizing tool) is an interesting support for different direct training actions.

\subsection{Design modifications}

Plant design modifications also need dynamic analyses. The goal of these studies is to establish the impact that modifications in components or systems have on the interactive global operation of the plant. Among these studies, those related to set-point adjustment, as well as those originated by important technological changes, are the most significant. Projects such as the replacement of SGs, the digitalization of the feed-water (FW) system control, or power upgrading have required prior developments of the model so that it could give quite a complete image of predicted plant behavior.

\subsection{Improvement of plant availability}

Integral plant models were prepared in the past to tackle safety issues and they continue being valid for these purposes. The wide use that they have had in all types of dynamic analysis of real or hypothetical plant behavior has made them a valid tool for the improvement of availability or to reduce the number of unnecessary reactor shutdowns. This capacity, usually implemented through control improvement, allows 
safety interests to be combined with those of productivity and competitiveness $[13,16]$.

\section{PROCEDURE AND PROJECTS}

In order to fulfil the above-mentioned tasks, usually devoted to the analysis of either transients that have actually occurred in the plant or hypothetical ones, some guidelines must be followed by the thermal-hydraulic analyst.

This section, as the previous one, is not a full description of procedures and projects. It adds some considerations on the most specific features involved. Documents like $[7,22]$ are giving guidelines and suggestions to carry out analysis tasks. They cover all aspects including preparing and maintaining models, performing calculations, and documenting results. Only two considerations need to be added in this case.

The first consideration that influences this analyst's work is the fact of being a member of an engineering team that supports plant operation. The analyst works in close contact with other engineers managing systems, equipment, licensing, reload planning, or quality assurance. As said in the introduction, the operation support analyst shares objectives with the engineering team that assists plant operation by means of engineering studies and decision-making.

The second consideration is related to ANAV-UPC model qualification procedure. This procedure shares basic aspects with many others and has some specific steps related to taking advantage of plant experiences for model qualification. It is described in [19] and currently followed by the team.

All of these tasks have been carried out in ANAV by two analysts (one per reactor as the 2 units of Ascó are almost identical) for the whole 1985-2001 period. External help from engineering companies was used when necessary. The most significant projects developed by the ANAV team with the aim of supporting plant operation are listed below in order to give some idea of the variety and depth of the analyses carried out.

(i) 1987-1989: analysis of incidental events at Ascó NPP $[4,12]$.

(ii) 1989: analytical support to the licensing of the AMSAC system (mitigation of transients without reactor trip) for Ascó NPP.

(iii) 1989-1990: thermal-hydraulic study of sequences for Ascó NPP PSA.

(iv) 1990: analysis of different alternatives to simulate the behavior of the Ascó secondary system.

(v) 1990-1991: analysis of the impact of SG tube plugging on the dynamic behavior of Ascó NPP.

(vi) 1991: analytical support for a "valve wide open test" of Ascó NPP turbine (in cooperation with Westinghouse).

(vii) 1992: analysis of Ascó NPP capabilities to face blackout scenarios.

(viii) 1993-1994: analytical support to the improvement of pressurizer level control at Ascó.

(ix) 1993: EOP's verification for Vandellòs-II NPP. (x) 1994-1996: analytical support to SG substitution at Ascó NPP coordinated with the design team (consortium Siemens-Framatome) and the companies responsible for licensing (ENUSA and Westinghouse).

(xi) 1993-1994: analytical support to FW control system digitalization and improvement for Ascó NPP.

(xii) 1995: pretest analyses of start-up tests at Ascó NPP with the new SGs.

(xiii) 1996-1997: improvement of the design of the main FW control system at Vandellòs-II NPP.

(xiv) 1997-1998: implementation of RELAP5/MOD3.2NPA for personal computers (collaboration with the engineering company PMSA) [18].

(xv) 1998: reanalysis of AMSAC behaviour after SG substitution at Ascó NPP [9].

(xvi) 1999-2000: advanced qualification, validation and documentation of thermal-hydraulic models at Ascó and Vandellòs-II NPPs [19].

(xvii) 1999-2000: analysis of the operating event occurring at the start-up test of cycle 13 at Ascó-II.

(xviii) 1999: thermal-hydraulic verification of interactive graphic simulators at Ascó and Vandellòs-II NPPs.

(xix) 1999-2001: update of thermal-hydraulic study of sequences for Ascó NPP probabilistic safety assessment.

(xx) 1999-2001: update of thermal-hydraulic study of sequences for Vandellòs-II NPP probabilistic safety assessment.

(xxi) 1998-1999: analytical support to Ascó NPP uprating.

(xxii) 1998-1999: analytical support to Vandellòs-II NPP uprating.

(xxiii) 2000-2001: analysis of the operating event occurring at Ascó-II on August 6th, 2000 [13].

Most of these analyses have produced reports that were subsequently dealt with either internally (by other ANAV branches such as PSA, licensing, fuel management, instrumentation and control, operation, and training) or externally (by the regulatory body, the fuel supplier or the engineering companies involved in developing associated subjects).

The three following sections are aimed at presenting some practical examples of this kind of analysis. The first is related to an actual transient (Section 4), the second to helping dialogue with the regulatory body (Section 5), and the third to an EOP/PSA transient (Section 6). The examples are presented in order to emphasize all the features that connect thermal-hydraulic analysis with operational concerns. More detailed information on the analysis can be found in specific calculation reports.

\section{EXAMPLE OF AN ACTUAL TRANSIENT ANALYSIS: MAIN FW TURBO-PUMP TRIP WITH SCRAM CAUSED BY A HIGH-LEVEL SIGNAL IN AN SG}

The selected transient took place in Unit 2 of Ascó NPP on August 6th 2000 [13]. The transient started with the trip of the main FW turbo-pump B when the plant was operating at steady-state nominal power. An automatic turbine run-back took place at $200 \%$ per minute until a load reference value 


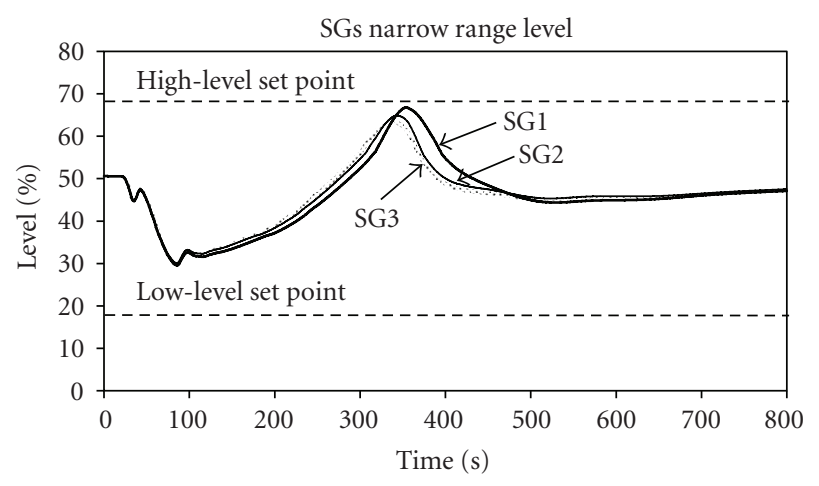

FIGURE 3: SGs narrow range level (FW turbo-pump generic transient).

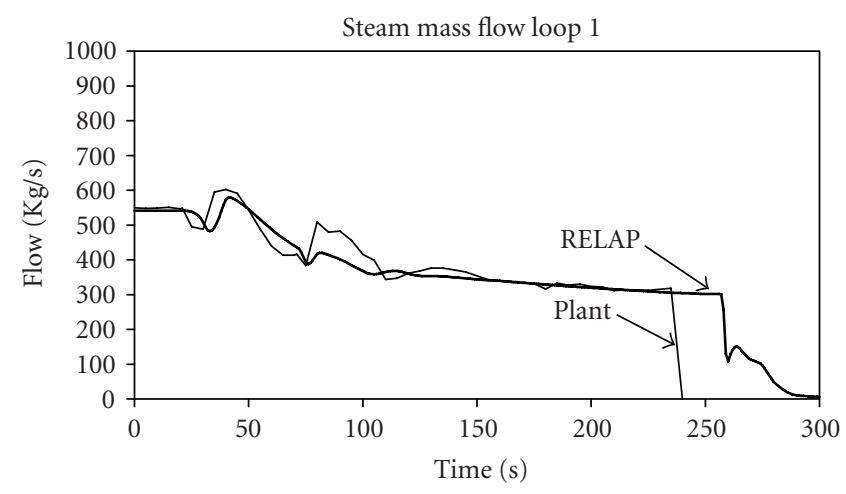

FIgURE 4: Steam mass flow loop1 (FW turbo-pump actual transient).

of $70 \%$ was reached. Both the steam-dump and rod control systems actuated in order to compensate the load rejection. At the same time, the main FW control system required an increase in the speed of turbo-pump A and the opening of FW valves to avoid a decrease of SG levels.

Subsequently, a first manual action was taken, consisting of an additional manual run-back of about 14\%, with a new automatic steam-dump opening. SG levels decreased and reached their minimum values of $18 \%, 20 \%$, and $26 \%$.

At this point, a second manual action took place, as a rapid increase in level was noticed in all SGs (150 seconds). The operator then manually closed the main feed water valve in loop 3 by about $20 \%$. Under these conditions, the level of SGs 1 and 2 increased quite quickly and the automatic control produced a closing signal for the related valves (200 seconds). The flow increased unexpectedly in loop 3, still under manual control, and its level subsequently rose until it produced a reactor trip due to a high-level signal (Figure 5).

The unexpected flow increase was the concern of the operation team. A main FW turbo-pump trip usually leads to a turbine run-back and to renewed stability at lower power which allows the scram to be avoided. The behavior of the plant seemed, a priori, abnormal.

To start with the analysis, the available technical information was studied. The first available block consisted of general

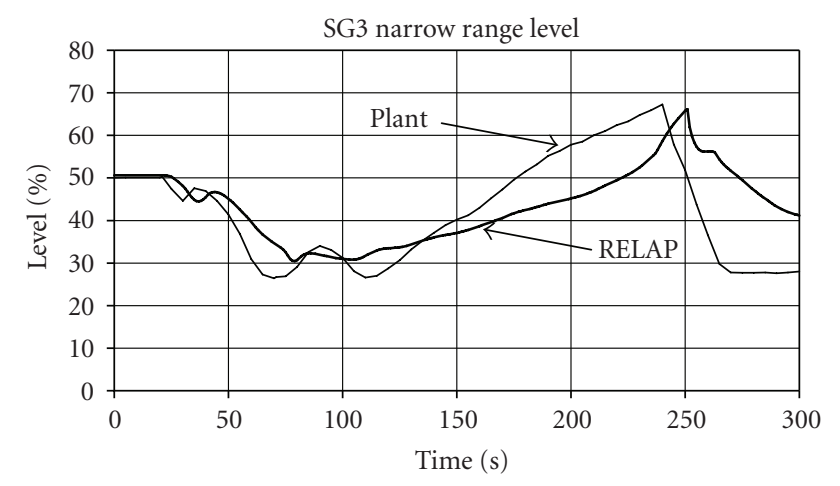

FIGURE 5: SG3 narrow range level (FW turbo-pump actual transient).

information on the description of the systems involved. It included

(i) turbine run-back system description,

(ii) main FW system description,

(iii) types of run-back,

(iv) run-back due to main FW turbo-pump trip.

Some functional features were also analysed such as

(i) main FW system layout,

(ii) performance with only one FW turbo-pump/transition,

(iii) common FW header effect.

As the analyst belonged to the engineering team supporting plant operation, system characterization and functional aspects were easily identified by means of first-hand contact. The run-back system was fully implemented in the model. FW turbo-pumps were included using the RELAP5 "pump" component and characterized by all necessary mechanical parameters.

The effect of the common header was experienced in the plant. It consisted of the fact that the partial closure of any FW valve produces an increase in the pressure upstream (header pressure) and, consequently, an increase in the flow through the other valves. Although Figure 2 is only a diagram of FW system, it helps to understand the layout of the header and valves and the phenomenon itself.

Post-trip information, including the sequence of events and time-histories of the main variables, was available and helpful to assess the plant model. Time histories are easily converted to time graphs for discussion and for comparison (Figures 4 to 7 include such data). The package also includes operator reports, which are structured information produced following an established procedure that is applied immediately after the transient occurs. It comprises control room display values, parameters, and alarms and also a brief description of manual actions taken by the operators.

In this case, as can be seen in Figures 6 and 7, a sharp inflexion appears in the loop $1 \mathrm{FW}$ mass flow graph (A), while two of them appear in loop 3 (B and C). Only B was easily identified as the manual closure of the loop $3 \mathrm{FW}$ valve. It was suspected that A could have been an automatic action, 


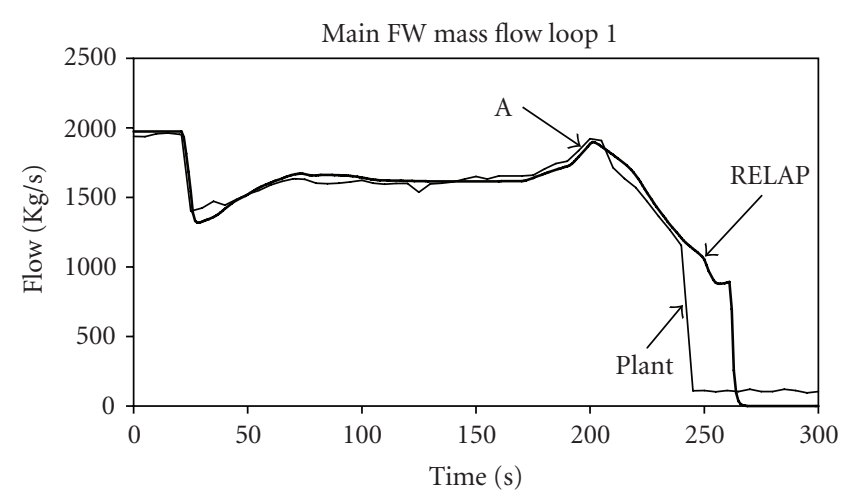

FIgURE 6: Main FW mass flow loop 1 (FW turbo-pump actual transient).

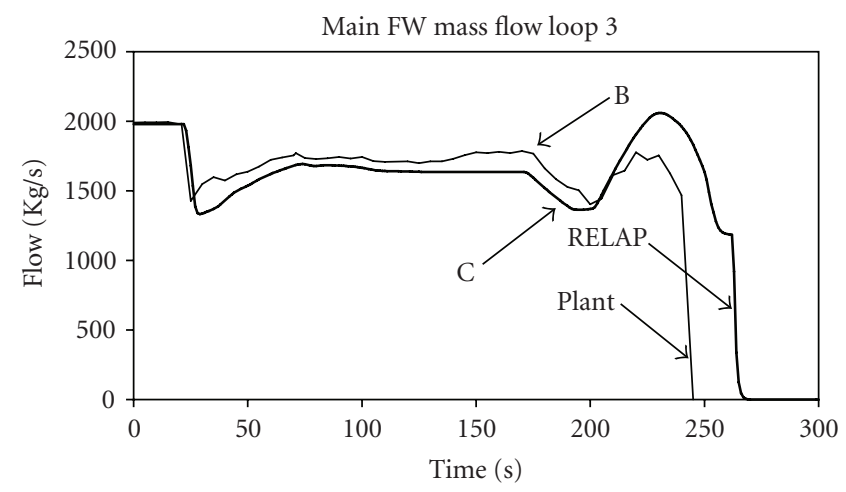

FIgURE 7: Main FW mass flow loop 3 (FW turbo-pump actual transient).

as the operator report made no reference to it. Event $\mathrm{C}$ was not identified at first by the operation team.

The subjects and questions that arose both internally (first) and externally (later on) by the safety authority were the following.

(1) Was the reactor scram really due to SG high level?

(2) The run-back system is designed to avoid reactor scram. Was it properly set up?

(3) Was the trip due to loop asymmetry?

(4) Was it due to the additional run-back?

(5) The FW closure did not seem to be related to a highlevel signal.

(6) At least 3 sharp inflexions appear in the post-trip FW flow time histories. Detailed identification is needed.

In order to answer the above questions some calculations were performed:

(a) generic turbo-pump trip with actual geometry of the real plant,

(b) turbo-pump trip with additional manual run-back,

(c) turbo-pump trip with additional manual run-back and partial manual closure of FW 3.

Calculation (a) was performed with the turbo-pump trip as the only specific boundary condition. The nodalization was modified to take into account the geometry of actual FW pipes in the real plant (they are different depending on the loop they belong to). The conclusions of this first calculation were that although the subsequent level oscillation comes very close to the high-level set point (Figure 3), the run-back system seemed to be correctly designed since it avoids scram. In addition, asymmetry produced some deviation among maximum values of each loop, but not a great one. The calculation results help to answer questions (1), (2), and (3).

In calculation (b), an additional manual run-back at time 71 seconds, was simulated. For possible comparisons, the development performed for the previous transient was kept, although it was not necessary. The additional run-back did not produce either a low or high SG level. Cases (a) and (b) were so similar that we do not show a figure for the latter, although a certain improvement of the margin was appreciated. Calculation (b) provided the answer to question (4).

In calculation (c) both manual actions were simulated as they occurred in the actual transient:

(i) additional manual run-back at 71 seconds,

(ii) FW 3 partial manual closure at 150 seconds.

The results can be appreciated in Table 2 and Figures 4-7.

The observed inflexion $\mathrm{C}$ (Figure 7) finally was the result of two combined effects. $\mathrm{C}$ was partially due to the impact of the automatic closure of loops 1 and 2 on loop 3. Inflexion $\mathrm{C}$ was also caused by the fine mechanism of partially closing a valve from the control room. This operation always shows a period of closure and a subsequent release of the driving device. Different attempts had been tested reasonably combining different times of closure/release. Calculation (c) uses the best combination of them and explains what could have happened in the plant.

Therefore, in order to draw conclusions on the actual capabilities of a protection system, many apparently nonsignificant engineering features must be clarified. The information produced allows the adequacy of run-back design to be corroborated and helps to enhance the database of useful experiences.

The follow-up actions arising from this analysis started from the fact that design adequacy is confirmed by the results of the calculations. No actions were taken on cause analysis, or design limits. Furthermore, no design or procedure modifications were needed. The only action taken was focused on informing on "lessons learned" about run-back effectiveness and on the fine behavior of main FW valves.

The transient, in any case, was significant enough to be included in the qualification matrix of the Ascó NPP plant model.

\section{EXAMPLE OF A HYPOTHETICAL TRANSIENT ANALYSIS: LOSS OF MAIN FW WITHOUT SCRAM}

The scenario selected for this example was related to the characterization of ATWS mitigation system actuation circuitry (AMSAC), a system designed to mitigate the consequences of anticipated transients without scram (ATWS). It is an example of a calculation [9] aimed at providing the grounds for dialogue with the safety authority. AMSAC adequacy is regulated following a procedure based on two different premises 


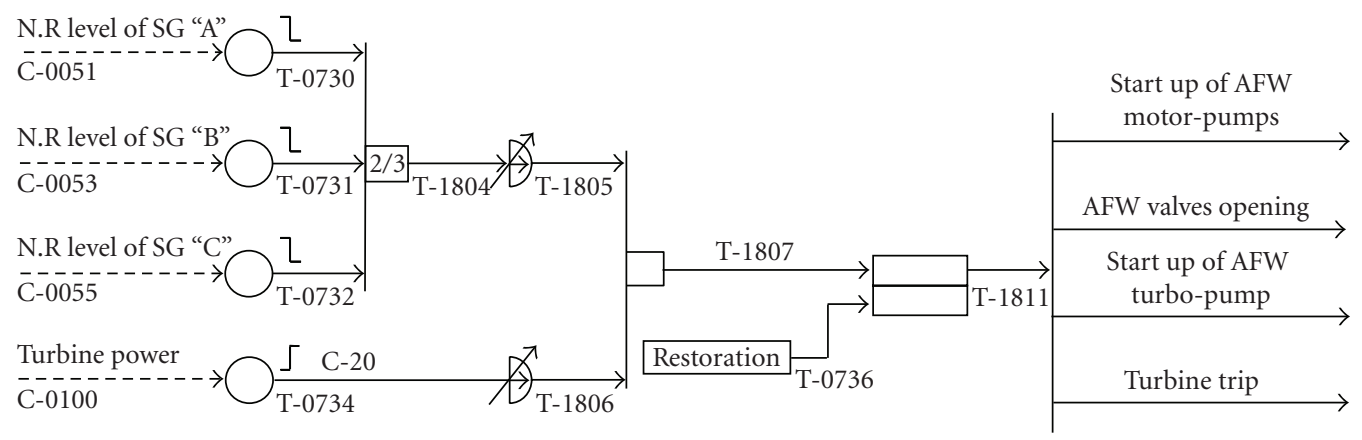

FIgURE 8: Logic diagram of the AMSAC system.

TABLE 2: Sequence of events for FW turbo-pump actual transient.

\begin{tabular}{lcc}
\hline Event & $\begin{array}{l}\text { Recorded } \\
\text { time }(\mathrm{s})\end{array}$ & $\begin{array}{l}\text { Calculated } \\
\text { time }(\mathrm{s})\end{array}$ \\
\hline Main FW turbo-pump stop & 21 & 21 \\
Run-back automatic signal & 22 & 22 \\
Additional manual run-back & 71 & 71 \\
Manual closure of FW 3 & 150 & 150 \\
Automatic closure signal of FW1 and 2 & 201 & 196 \\
Reactor scram due to high SG3 level & 240 & 249 \\
\hline
\end{tabular}

or statements considered as the starting point of the analysis/discussion. The premises are

(i) an existing generic assessment establishes the effectiveness of the combined effect of the AMSAC and inherent nuclear feedback [20] such as moderator temperature coefficients of current core designs to reduce power thus ensuring that primary pressure peak remains below design limits,

(ii) PSA models show reasonably high results for reactor protection system (RPS) reliability.

These two statements are accepted and supported by previous calculations that are not part of this analysis. The first statement defines the generic licensing and the second one is a kind of requirement needed to start dialogue.

The current analysis is devoted to extend generic results to future core designs. Thus, if future core designs maintain or improve feed back effects of current design, the effectiveness of mitigating actions is ensured. All of this will induce the regulatory body and licensee to discuss how a plant such as Ascó or Vandellòs-II (with a definite core design and relief capacity) fits within the generic assessment.

Transients without scram are managed by using core feedback effects. AMSAC protection is designed to improve the success of the strategy. In any transient in which primary pressure and temperature are allowed to increase, there is a risk of overpressure that needs to be both studied and controlled.

The general philosophy of the protection is to use the effects of fuel and moderator feedback in order to produce a power decrease at an initial stage, and subsequently, at a sec- ond stage, to allow normal relief systems to maintain primary pressure within mechanical limits established by the ASME code. Thus, protection features together with relief capacity have been tested in this study.

The transient presented below is a loss of FW without scram, as this case is traditionally considered to be the most crucial scenario among those initiated by a condition II event. For a given plant, it must be demonstrated that by following this event and assuming RPS failure, the reactor power decreases and primary pressure does not exceed the ASME limit.

The logic of the protection system can be followed in the corresponding diagram (Figure 8). An AMSAC signal is produced when 2 out of 3 narrow-range SG level signals become lower than the so-called low-low set point. This signal is delayed a few seconds and it activates the turbine trip and the automatic start-up of the auxiliary feed-water (AFW). At a first stage the turbine trip produces a pressure and temperature increase leading to power reduction (through feed-back effects) and the AFW start-up at the second stage helps to recover the plant. The delay must be properly tuned in order to fulfil the mitigation goal.

In order to simulate the transient and to characterize the protection actuation, some relevant aspects have to be taken into account, basically neutronic feed-back, signal delay, primary relief capacity, heat transfer from primary to secondary side, and secondary relief capacity.

Neutron-kinetics and thermal-hydraulics are coupled in this case. Fortunately, the transient is symmetric and zero-D kinetics with enhanced fuel and moderator tables were the suitable option. Although standard information from the core designer [21] is related to operation ranges for reactivity feedback, improved tables were available covering wide ranges of moderator densities. Fuel effect is also relevant, but it was not necessary to include additional information to the kinetic model.

Several calculations were performed in order justify the signal delay proposed by the designer. Once the behavior of the involved systems was characterized, two calculations were performed: one with and one without protection actuation. For simplicity, only the results of the first calculation are presented. Figure 9 shows moderator average temperature and nuclear power. An increase in the moderator 


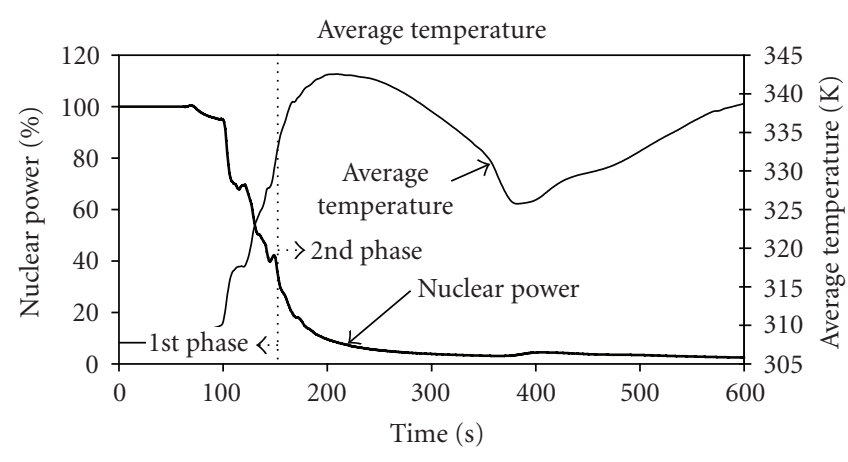

FIgURE 9: Average temperature and nuclear power (AMSAC transient).

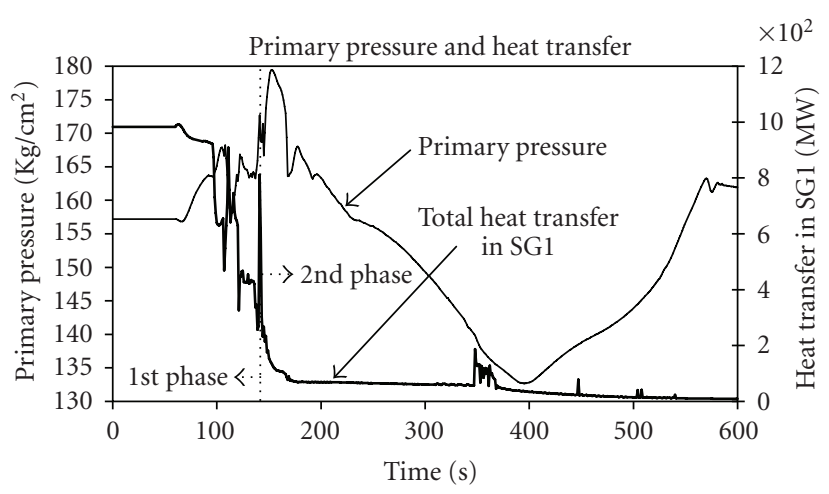

FIGURE 10: Heat transfer in SG1 and primary pressure (AMSAC transient).

temperature results in a decrease of nuclear power. Figure 10 shows heat transfer in SG1 and primary pressure. Heat transfer decrease during the first phase causes an increase in average moderator temperature. Heat transfer in the second phase remains at a nonzero value, which contributes to energy extraction and results in a primary pressure peak of about $17.95 \mathrm{MPa}$, which is clearly lower than the ASME limit (3200 psia or $22.06 \mathrm{MPa}$ ). The pressure peak evaluated in the base calculation without AMSAC activation showed a value of $21.81 \mathrm{MPa}$.

The results prove, for the considered core design,

(i) the effectiveness of AMSAC system,

(ii) the capability of relief and safety valves to mitigate pressure peak.

The study is an illustration of the usefulness of a BE plant model with a rather simple but effective coupled neutronics. It is also an example of how calculations result could provide the basis for dialogue with the regulator. The BE prediction of the scenario helps characterizing the interactive behavior of the involved systems.

\section{EXAMPLE OF AN EOP/PSA TRANSIENT ANALYSIS: TOTAL LOSS OF FW}

EOP/PSA transient analyses are the most usual studies that are traditionally performed using integral plant models.
Analytical support for EOPs development is a very complex task requiring a great deal of effort. A specific IAEA report [23] establishes the tasks related to such activity which currently involves different organizations. ANAV-UPC coordinated team has been in many occasions the responsible of validation analyses.

The selected group of scenarios for this example is the "total loss of FW," which occurs due to a main FW turbopump trip or due to a malfunction of the main FW valves [10].

The generic information available consists of the description of the feed and bleed (F\&B) procedure, as well as the description of the systems involved.

The simultaneous failure of the AFW system causes loss of the heat sink and, shortly after, both the turbine and the reactor trip.

The operators start following the EOP "Reactor trip and/or Safety Injection." The first steps of this EOP verify the function of the AFW and try to ensure recovery. As Ascó EOPs are symptom oriented, the minimum time for transfer to the specific EOP "loss of heat sink" is quite long (about 10 minutes). For all this period of time, the level of the steam generators will uniformly decrease. Once the wide-range level of 2 out of 3 SGs becomes less than $6 \%$, it is time to start the $\mathrm{F} \& \mathrm{~B}$ procedure: reactor coolant pumps (RCPs) are tripped, 2 out of 2 pressurizer power operated relief valves (PORVs) are opened and high pressure injection system (HPIS) is activated.

After a period of time, the plant will be cooled down and the final steps of the procedure aim to properly stop the HPIS and to close PORV once the plant has been recovered (EOP "Finalizing Safety Injection").

The objective of the analysis is to prove the effectiveness of the primary $\mathrm{F} \& \mathrm{~B}$ procedure and to answer questions and subjects, set by both the operation and PSA groups, related to

(i) timing evaluation,

(ii) possibility of successfully executing the procedure having only 1 relief valve available.

The scenario selected as the base case for this analysis has the following features and assumptions:

(i) loss of FW at time 50 seconds,

(ii) failure of 1 out of 2 HPIS trains and the availability of only one single PORV,

(iii) AFW and steam-dump unavailable,

(iv) no recovery actions are assumed.

Manual actions are the following:

(i) at time 350 seconds RCPs are stopped and their coast down is initiated;

(ii) time to start the procedure is set to the minimum reasonable time, 600 seconds, (i.e., 600 seconds after the wide-range level of 2 out of 3 SGs reaches $6 \%$, PORV is opened and HPIS is actuated).

After the total loss of FW takes place, heat transfer from the primary to the secondary side degrades and causes a decrease of the SG level. Once this symptom has been detected, 


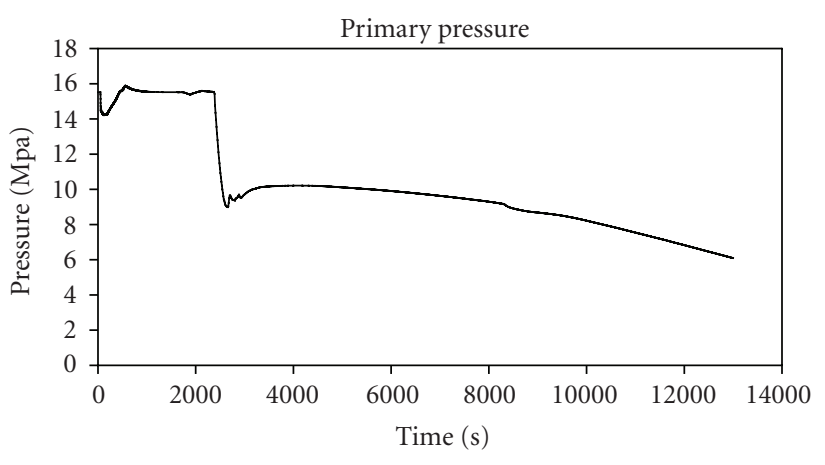

FIGURE 11: Primary pressure (F\&B base case).

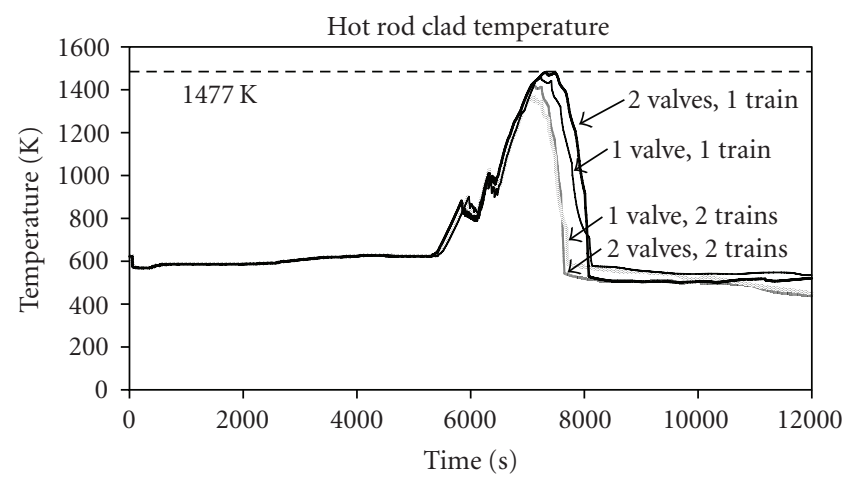

FIGURE 12: Hot rod clad temperature (F\&B availability study).

the procedure starts by opening 1 PORV and actuating 1 HPIS train. Water injected into the primary system at low temperature is heated by decay power and comes out through the relief valve. The procedure results in a pressure decrease (see Figure 11), which means that energy produced is completely extracted.

The base case brings the plant to a safe situation without violating design limits as hot rod clad temperatures show a general decreasing trend during the whole transient. The calculation properly captures the main relevant thermalhydraulic features of the scenario.

Once the base case has been successfully simulated, a strategy is defined to answer the following:

(i) impact of PORV and HPIS partial availability (less than 2 PORV or 2 HPIS trains),

(ii) maximum time to start the procedure after the level symptom occurs,

(iii) relevant heat sink recovery phenomena (although recovery actions are quite fast, they involve different components and need some time).

If the answers to the questions above are obtained, the operation team will have a better general picture of the scenario and related phenomena. As obviously each answer has an impact on the others, the strategy applied is to launch quite a large number of combined scenarios in order to cover different situations that could potentially occur. For a given combination of component availability, a series of different

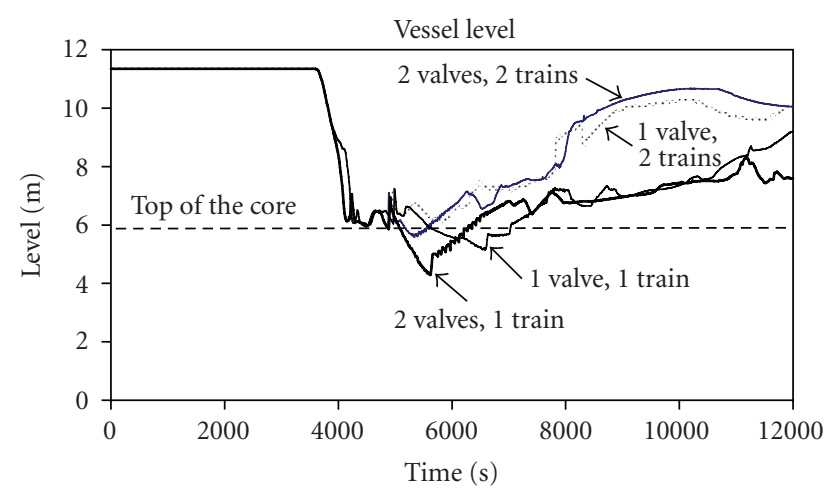

FIGURE 13: Reactor vessel level (F\&B availability study).

procedure starting times have been tried and for each of these calculations heat sink recovery was also imposed at different times.

The total number of cases was 61 . The following paragraphs show the most relevant results of the study.

Two findings were identified in the sensitivity study regarding the impact of the partial availability of PORVs and HPIS trains. Stress must be laid on the word "identified" as this is the aim of a study oriented, as a first approach, to operation support.

(i) The first finding is related to the connection between operation and PSA. With the availability of one PORV and one HPIS train, the plant can be recovered (Figure 12). Although this statement is made based on multiple calculations sweeping over different ranges of operation boundary conditions, it is still pending further analysis (basically uncertainty evaluation).

(ii) The second is related to an interesting phenomenon that takes place in the transients with the availability of 2 valves and 1 train. In this transient the depressurization rate is high (2 valves) and water supply is low (1 train). High depressurization instantly affects all the primary circuit, produces a lower saturation temperature and helps steam generation in the core. This result does not seem critical at all, as it only causes a small peak of temperature quite within design limits and it is a useful result for operation, as it explains a nonintuitive situation: the Reactor Vessel Level Instrumentation System (RVLIS) implemented in Ascó NPP can supply a lower level value in a situation with higher availability of components (see Figure 13).

A second sensitivity study was performed to establish the maximum time to start the procedure.

Figure 14 shows the hot rod clad temperature for a selected group of transients described in Table 3. In 2 out of 4 cases (time to start procedure after symptom equals $600 \mathrm{~s}$ and $3000 \mathrm{~s})$ the maximum temperature remains below $1477^{\circ} \mathrm{K}$ $\left(2200^{\circ} \mathrm{F}\right)$. In the case of a delay of $5700 \mathrm{~s}$ the clad temperature goes slightly beyond this limit and plant recovery is not successful. In between, there is a case that needs further analysis (a delay of $5100 \mathrm{~s}$ ). 
TABLE 3: Features of selected transients ( $F \& B$ starting time analysis).

\begin{tabular}{|c|c|c|c|c|}
\hline & \multicolumn{4}{|c|}{ Starting time of the F\&B procedure (s) } \\
\hline & Case $1600 \mathrm{~s}$ & Case $23000 \mathrm{~s}$ & Case $35100 \mathrm{~s}$ & Case $45700 \mathrm{~s}$ \\
\hline $\begin{array}{l}\text { Main FW turbo- } \\
\text { pumps stop }\end{array}$ & 50 & 50 & 50 & 50 \\
\hline $\begin{array}{l}\text { Turbine and reactor } \\
\text { stop }\end{array}$ & 50 & 50 & 50 & 50 \\
\hline $\begin{array}{l}\text { Manual action: RCP } \\
\text { stop }\end{array}$ & 350 & 350 & 350 & 350 \\
\hline $\begin{array}{l}2 \text { out of } 3 \text { SG wide } \\
\text { range level reach } 6 \%\end{array}$ & 1782 & 1782 & 1782 & 1782 \\
\hline $\begin{array}{l}\text { Manual action: PORV } \\
\text { is opened }\end{array}$ & 2382 & 4782 & 6882 & 7482 \\
\hline $\begin{array}{l}\text { Manual action: HPIS } \\
\text { is actuated }\end{array}$ & 2382 & 4782 & 6882 & 7482 \\
\hline $\begin{array}{l}\text { Clad maximum tem- } \\
\text { perature is reached } \\
\text { (clad maximum } \\
\text { temperature) }\end{array}$ & $48(622 \mathrm{~K})$ & $4220(628 \mathrm{~K})$ & $7240(1460 \mathrm{~K})$ & $7610(1652 \mathrm{~K})$ \\
\hline Transient end & 13000 & 13000 & 13000 & 13000 \\
\hline
\end{tabular}

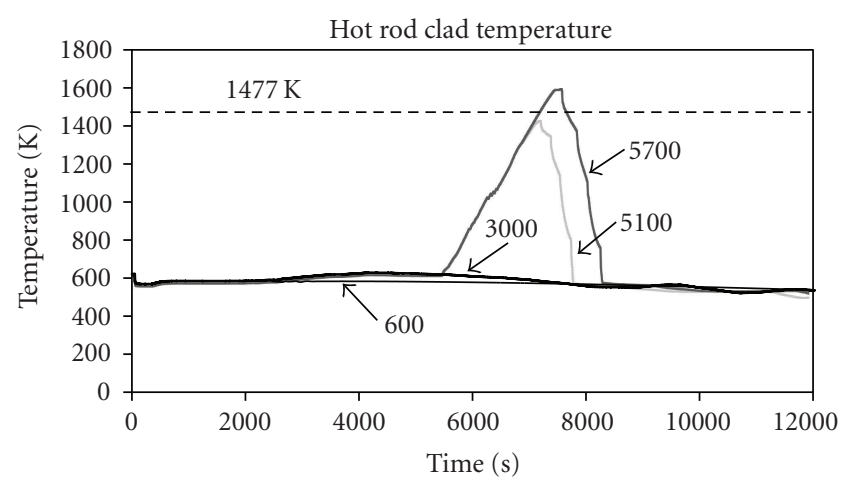

FIGURE 14: Hot rod clad temperature (F\&B starting time analysis).

This study establishes a first approach for the maximum time available for starting the $F \& B$ procedure $(5100 \mathrm{~s}$ ) and bringing the plant to a safe situation. This result is interesting not only for PSA, but also for operation and training. Nevertheless, as it is just a first-approach calculation, it needs to be confirmed after evaluating the associated uncertainty.

The sensitivity study aimed at analysing heat sink recovery actions provides quite useful information for operators, as it establishes the relationship between the actions performed and trends and data that can be observed in the control room. This point is especially interesting in operation and training, even though Ascó EOPs are symptom oriented.

The clad temperatures of the selected case with and without heat sink recovery are shown in Figure 15. On the one hand, the transient without heat sink recovery shows a short partial core uncover with a corresponding temperature increase, but ends in a safe situation. On the other hand, the transient with heat sink recovery at $4500 \mathrm{~s}$ completely prevents the mentioned increase.

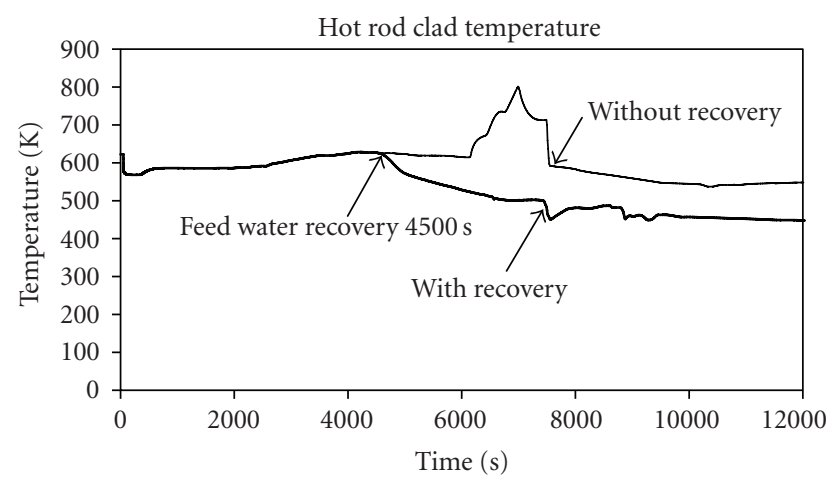

Figure 15: Hot rod clad temperature (F\&B heat sink recovery analysis).

The results obtained in the study of the group of scenarios of "Total loss of feed water" for Ascó NPP are valuable for the safe operation of the plant.

The analysis provides answers for different operation questions about the studied scenarios and produces a better general picture of the group of transients and related phenomena. It also helps to get a better understanding of PSA results, as they are corroborated.

The analysis identifies, among all the transient runs performed, those that require further study of the uncertainty evaluation. Future work on this point can be straightforwardly directed to recognized calculations.

\section{CONCLUSIONS}

Dynamic analysis supporting plant operation is an engineering task that shares objectives with other engineering branches that support plant operation. It is connected with 
different technical features of plant design and produces results that are useful for safety, operation, design and training.

ANAV has had an important advantage by having its own analysts on its technical staff. As members of the corresponding engineering team, the analysts have been essential in order to smooth the relationship between different organizations involved in the most important decisions taken related to the operation and safety of the Ascó and Vandellòs-II reactors.

The main tool of this type of analysis has been the integral plant model. After 15 years of these practices, nodalizations have been maintained and improved at a quality level to ensure optimum performance. During all this time ANAV analysts have worked together with the UPC team at different levels. Innovative engineering and research compose the scope of analytical activities that have resulted fruitful for both the utility and the university.

Anticipating expected behaviour has revealed itself to be extremely useful for operation support and decision-making. Some results of the analysis performed were crucial at the time they were produced, such as the impact of SG tube plugging on the dynamic behaviour of Ascó NPP. Some were complete and helpful for safety, such as support to the licensing of the AMSAC system. Some others were a combined effort by different organizations, such as the analytical support to SG substitution at Ascó NPP. The more the nodalizations are used by qualified users with a deep knowledge of them, the more accurate and useful they become, not only for safety issues, but also for issues related to operation and engineering.

The study fulfils its objective of illustrating the usefulness of computational analysis for operational support.

\section{ACRONYMS}

AFW: Auxiliary feed water

AMSAC: ATWS mitigation system actuation circuitry

ANAV: Asociación Nuclear Ascó-Vandellòs

ATWS: Anticipated transient without scram

ASME: American standards of mechanical engineering

BE: $\quad$ Best estimate

BEPU: Best estimate plus uncertainty

EOP: Emergency operating procedures

F\&B: $\quad$ Feed and bleed

FW: $\quad$ Feed water

HPIS: High pressure injection system

NPP: Nuclear power plant

PORV: $\quad$ Power operated relief valves

PSA: Probabilistic safety analysis

PWR: Pressurized water reactor

RCP: Reactor coolant pump

RPS: Reactor protection system

RVLIS: Reactor vessel level instrumentation system

SG: $\quad$ Steam generator

UPC: Technical University of Catalonia

\section{REFERENCES}

[1] F. Reventós and C. Llopis, "Benefits of using integral plant models in utilities availability and safety issues," in Proceedings of Workshop on Advanced Thermal-Hydraulic and Neutronic Codes: Current and Future Applications NEA/CSNI/R(2001)2, vol. 1, pp. 395-407, Barcelona, Spain, April 2000.

[2] F. Reventós, J. Sánchez-Baptista, A. Pérez-Navas, and P. Moreno, "Transient analysis in the Ascó NPP using RELAP5/MOD2," Nuclear Technology, vol. 90, no. 3, 1990.

[3] C. Llopis, J. Pérez, and R. Mendizábal, "Assessment of RELAP5/MOD2 against a turbine trip from $100 \%$ power in the Vandellòs-II NPP," International Agreement Report Nureg/ia108, Nuclear Regulatory Commission, Washington, DC, USA, June 1993.

[4] F. Reventós, J. Sánchez-Baptista, A. Pérez-Navas, and P. Moreno, "Assessment and application of blackout transients at Ascó nuclear power plant with RELAP5/MOD2," International Agreement Report Nureg/ia-119, Nuclear Regulatory Commission, Washington, DC, USA, June 1993.

[5] C. Pretel, Ll. Batet, A. Cuadra, et al., "Qualifying, validating and documenting a thermalhydraulic code input deck," in Proceedings of Workshop on Advanced ThermalHydraulic and Neutronic Codes: Current and Future Applications NEA/CSNI/R(2001)2, vol. 2, pp. 239-250, Barcelona, Spain, April 2000.

[6] A Petruzzi, F. D’Auria, T. Bajs, and F. Reventós, "International training program: $3 \mathrm{~d}$ s.un.cop-scaling, uncertainty and 3d thermal-hydraulics/neutronkinetics coupled codes seminar," in Proceedings of the 6th International Conference on $\mathrm{Nu}$ clear Option in Countries with Small and Medium Electricity Grids, Dubrovnik, Croatia, May 2006.

[7] R. Ashley, M. El-Shanawany, F. Eltawila, and F. D’Auria, "Good practices for user effect reduction," Status Report NEA/CSNI/R(98)22, Nuclear Energy Agency, Paris, France, November 1998.

[8] F. Pelayo and F. Reventós, "Current and anticipated uses of thermal-hydraulic codes in spain," in Workshop on Transient Thermal-Hydraulic and Neutronic Codes Requirements (OECD/CSNI '96), pp. 313-314, Annapolis, Md, USA, November 1997.

[9] P. Posada, F. Reventós, J. Sánchez-Baptista, J. Pérez-Navas, and P. Moreno, "Study of transients related to AMSAC actuation, sensitivity analysis," International Agreement Report Nureg/ia-0150, Nuclear Regulatory Commission, Washington, DC, USA, November 1998.

[10] F. Reventós, L. Batet, C. Pretel, M. Ríos, and I. Sol, "Analysis of the Feed \& Bleed procedure for the Ascó NPP. First approach study for operation support," Nuclear Engineering and Design, vol. 237, pp. 2006-2013, 2007.

[11] F. Reventós, L. Batet, C. Pretel, O. Llombart, I. Sol, and S. Romera, "Improving PSA usefulness using the results of thermal hydraulic best estimate models of ANAV reactors," in Technical Meeting on Effective Integration of Deterministic and Probabilistic Safety Analysis in Plant Safety Management, Barcelona, Spain, September 2006.

[12] F. Reventós, J. Sánchez-Baptista, A. Pérez-Navas, and P. Moreno, "Assessment of a pressurizer spray valve faulty opening transient at Ascó nuclear power plant with RELAP5/MOD2," International Agreement Report Nureg/ia-121, Nuclear Regulatory Commission, Washington, DC, USA, December 1993.

[13] F. Reventós, J. Posada, C. Llopis, C. Pretel, and P. Moreno, "Improving NPP availability using thermal hydraulic integral plant models. Assessment and application of turbine run-back scenarios," in Proceedings of the 9th International Conference on Nuclear Engineering (ICONE-9 '01), Nice, France, April 2001. 
[14] C. Llopis, A. Casals, J. Pérez, and R. Mendizábal, "Assessment of RELAP5/MOD2 against a main feed water turbo pump trip transient in the Vandellòs-II NPP," International Agreement Report Nureg/ia-110, Nuclear Regulatory Commission, Washington, DC, USA, December 1993.

[15] C. Llopis, J. Pérez, A. Casals, and R. Mendizábal, "Assessment of RELAP5/MOD2 against a 10\% load rejection transient from $75 \%$ steady state in the Vandellòs-II NPP," International Agreement Report Nureg/ia-109, Nuclear Regulatory Commission, Washington, DC, USA, May 1993.

[16] C. Llopis, F. Reventós, L. Batet, C. Pretel, and I. Sol, "Analysis of low load transients for the Vandellòs-II NPP. Application to operation and control support," Nuclear Engineering and Design, vol. 23, pp. 2014-2023, 2007.

[17] A. Cuadra, J.-L. Gago, and F. Reventós, "Analysis of a main steam line break in Ascó nuclear power plant," Nuclear Technology, vol. 146, no. 1, pp. 41-48, 2004.

[18] J. Posada, M. Martín, F. Reventós, and C. Llopis, "Interactive graphical analyser based on RELAP5/MOD3.2-NPA," in Proceedings of the 2nd CSNI Specialist Meeting on Simulators and Plant Analysers, Espoo, Finland, September 1997.

[19] F. Reventós, L. Batet, C. Pretel, M. Salvat, and I. Sol, "Advanced qualification process for ANAV integral plant models," Nuclear Engineering and Design, vol. 237, no. 1, pp. 54-63, 2007.

[20] W. S. Raughley and G. F. Lanik, "Regulatory effectiveness of the anticipated transient without scram rule," Tech. Rep. USNRC. Nureg-1780, Nuclear Regulatory Commission, Washington, DC, USA, April 2001.

[21] ENUSA, "Informe de Diseño Nuclear del Ciclo 13 de la C.N. Ascó-II,” ITEC-0779, December 1999.

[22] "Accident Análisis for nuclear power plants," Safety Reports Series 23, IAEA, Vienna, Austria, 2002.

[23] "Development and review of plant specific emergency operating procedures," Safety Reports Series 48, IAEA, Vienna, Austria, 2006. 

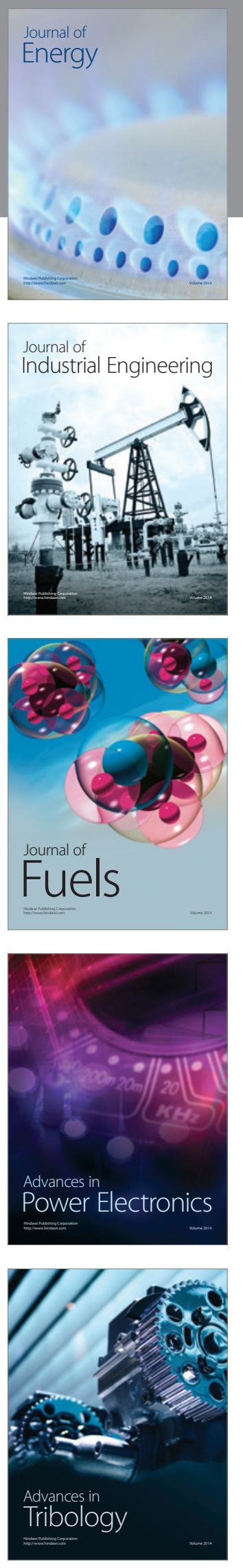
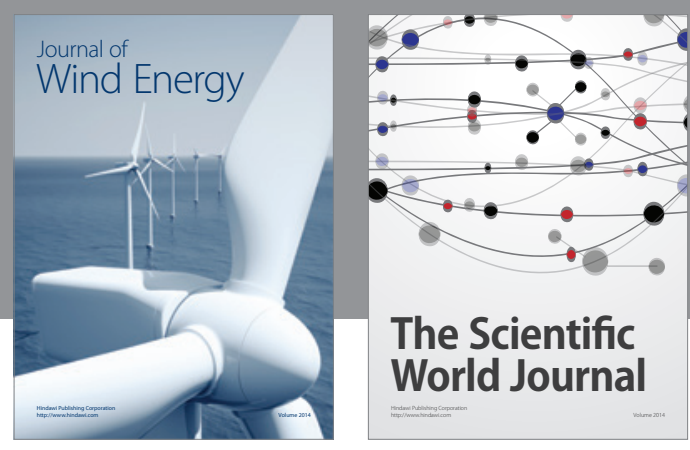

The Scientific World Journal

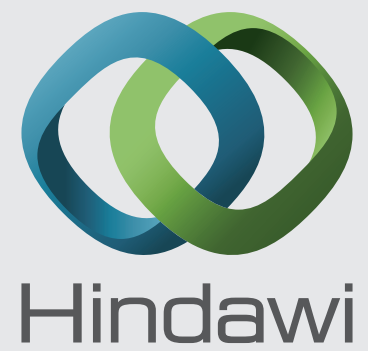

Submit your manuscripts at http://www.hindawi.com
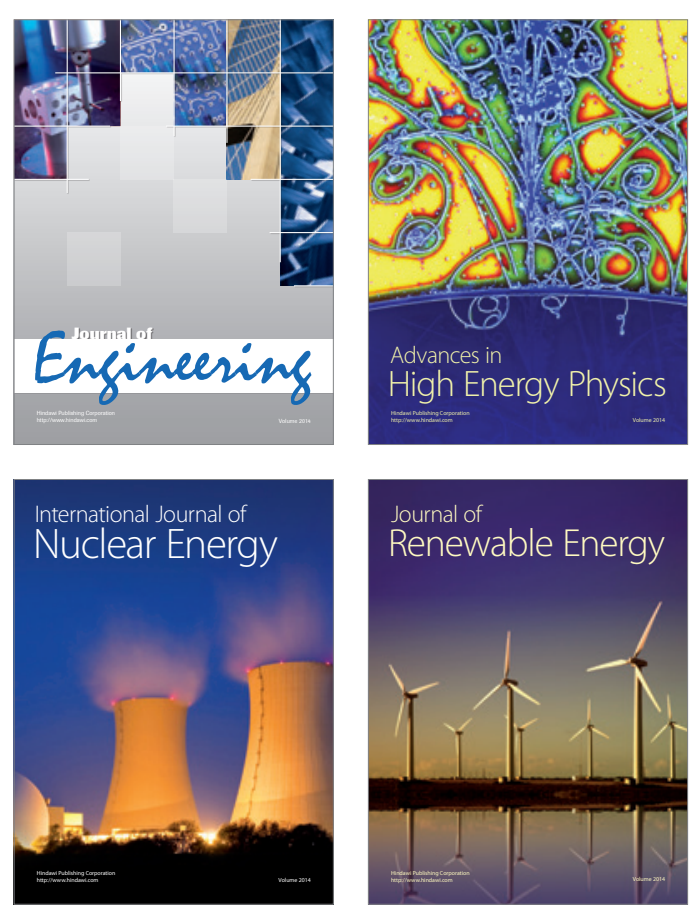

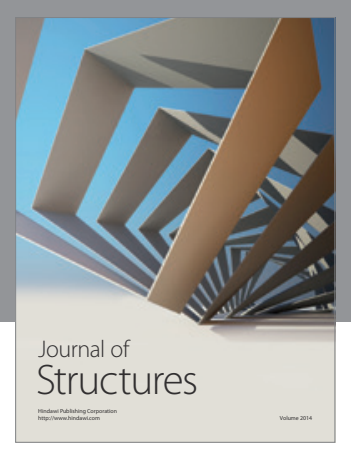

Rotating
Mechinery
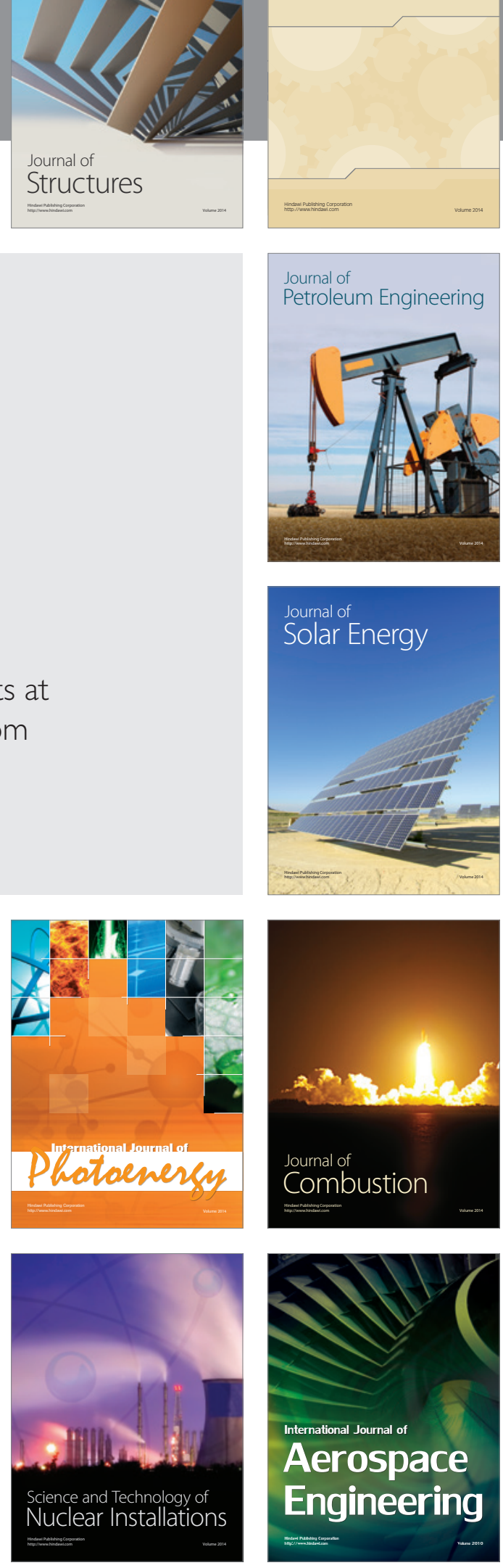